\title{
Circular economy assessment tool for end of life product recovery strategies
}

\author{
Yohannes A. Alamerew ${ }^{1}$ (D) - Daniel Brissaud ${ }^{1}$
}

Received: 3 December 2017 / Accepted: 15 October 2018 / Published online: 31 October 2018

(C) The Author(s) 2018, corrected publication 2019

\begin{abstract}
Circular Economy (CE) aims to maintain the value of products, components, materials, and resources in the economy for as long as possible. Current end of life (EoL) product circularity decision-making methods are focused on technical and economic factors neglecting other crucial areas such as legislative pressure and customer demand, which are pertinent in the decision-making process. This paper presents a decision-making method to evaluate end of life product circularity alternatives at strategic level. A Product Recovery Multi-Criteria Decision Tool (PR-MCDT) is proposed to evaluate product circularity strategies from an integrated point of view, i.e. by simultaneously taking into account technical, economic, environmental, business, and societal aspects. The paper also identifies key end of life decision-making factors to assess product recovery strategies. An illustrative example is presented and discussed to show the applicability of the tool for the selection of product recovery options. A PR-MCDT is used at the senior/middle management level to ensure strategic decisions, which then promote success of the company.
\end{abstract}

Keywords Circular economy $\cdot$ Remanufacturing $\cdot$ End of life strategy $\cdot$ Product recovery $\cdot$ Multicriteria decision methodology

\section{Introduction}

The global crisis in resource scarcity, population growth and climate change impacts are placing pressure to ditch the traditional "Make-Use-Dispose" economic model and adopt "make, use, return" as our collective mantra by joining the circular economy. The circular economy moves away from the traditional "take-make-dispose" economic model to one that is regenerative by design $[12,13]$. The main aim of the circular economy is considered to meet

Yohannes A. Alamerew

yohannes.alamerew@grenoble-inp.fr 
economic prosperity, while maintaining environmental quality and social equity to create sustainable world for future generations [23].

Circular economy aims to facilitate an effective flow of resources, keeping products, components and materials at their highest value at all times through the extension of product life times by repair, recondition and remanufacture as well as closing of resource cycles through recycling and related strategies [4]. Despite being proven to be both economically and environmentally beneficial, there are few successful examples, due to lack of analysis methods and tools that can assess different aspects of circular systems [3].

Product recovery has become increasingly important towards transitioning to a circular economy [2]. Product recovery management aims to close the loop throughout the product life cycle [26]. The implementation of extended producer responsibility (EPR) in new governmental legislation, together with the growing environmental and economic concern, demands that original equipment manufacturers (OEMs) to take care of their products after they have been discarded by the consumer $[18,41]$.

Product recovery management (PRM) is the management of all used and discarded products, components, and materials to recover as much of the economic and ecological value as possible thereby reducing the quantity of discarded waste [42]. End of life product recovery strategies include Remanufacture, Repair, Recondition, Cannibalization, Redesign, Refurbish and Recycle $[21,42]$. All these end of life options are distinct from one another and selecting the best suitable product recovery option should take several factors into consideration [27]. End of life in this work refers to the point in time when the product no longer satisfies the last user.

Current end of life product recovery decision-making approaches are centred on economic and technical factors [40] neglecting other equally influential aspects which are pertinent in the decision-making process such as market demand, social trends and legislative pressure. Additionally, there is lack of a holistic approach that uses an inclusive methodology to assess and evaluate recovery strategies from an integrated point of view i.e. by taking into account technical, economic, environmental, business and societal aspects simultaneously. The aim of this paper is to identify EoL decision-making factors and incorporate them into a holistic methodology to evaluate EoL product recovery strategies. The viability of a recovery strategy is evaluated against the relevant technical, economic, environmental, business and social criteria.

The rest of the paper is organized as follows. Section "Literature review" presents the literature review on EoL decision making approaches and strategic evaluation of recovery strategies. In section "Research methodology" the research methodology used to answer the research questions is described. In section "The proposed methodology and tool" the multicriteria decision-making approach is discussed, and key decision-making factors used to assess the feasibility of recovery strategies are presented. Subsequently in section "Case study", the application of the method on a case is discussed. Finally, conclusions are drawn by summarizing the main findings of the study.

\section{Literature review}

\section{End of life product recovery decision methods}

The literature survey shows that there is a wide range of EoL decision making methods which employ various approaches. Due to the variation of drivers and interested parties, a holistic decision approach is required. End-of-life decision-making needs to use a holistic approach to 
evaluate EoL strategies from various perspectives including environmental, economic, societal, business, technical, market and legislative aspects [36, 43].

The term end-of-life in this research work is referred when the product no longer satisfies the last user of the product at end-of-use. Therefore, it is referred on the last user of the product and the product fails to satisfy the end user. But, there are many researchers who define the term in reference to the first user of the product that makes some strategies like reuse and minor repair to be considered as end-of-life strategies. An EoL option is considered as a Product Recovery Strategy (PRS), if fulfils three main criteria's: collection of used products, reprocessing of a recovered product and redistribution of the processed product [42]. End-oflife product recovery strategies include Remanufacture, Repair, Recondition, Repurpose, Cannibalization, Redesign, Refurbish, Upgrading and Recycle [21, 42]. Even though, this is not an exhaustive list of PRS and some of the strategies overlap with each other. End of life decision-making approaches are comprehensively grouped into three main categories; optimization methods, multi-criteria decision methodology and empirical method.

\section{Optimization methods}

The decision of mathematical optimization methods uses optimization problems for choosing a suitable product recovery option for a typical product. Optimization methods are completely focused on cost and economic benefit while it lacks the ability to consider other unquantifiable factors $[10,16]$. Papers that employ mathematical models, mixed integer programming models and numerical models hold a significant majority in the EoL decision making process [40]. Furthermore, due to the complexity of mathematical models and the requirement of too many input parameters, it is found to be difficult for industries to effectively and efficiently use the proposed EoL decision-making tools.

\section{Multi-criteria decision methodology (MCDM)}

These multi-criteria methods have benefits due to the technical aspect and structure by simultaneously analysing quantitative and qualitative factors. MCDM also takes the preference of the user/decision-maker in the decision-making process [6, 24].

\section{Empirical methods}

In this method the decision for the appropriate product recovery option is made based on knowledge and experience gained from analysing successful cases of product recovery [39].

Table 1 presents end of life decision making methods in each category with the description of the usefulness of the method.

\section{Strategic decision of recovery strategies}

Strategic decisions within EoL product recovery assess the feasibility of recovery strategies for the business. Strategic evaluation is critical to ensure strategic decisions, which then promote success of the company [9]. Strategic decision of EoL products could be made prior to implementing a product recovery business; at the periodic stages to view whether it is having the desired effect on the business and at conceptual design phase particularly when they invested interests in business scenario such as product service system [16]. Several studies 
Table 1 End of life decision making methods

\begin{tabular}{|c|c|}
\hline Decision-making method & Description \\
\hline $\begin{array}{l}\text { Multi objective optimization decision } \\
\text { methodology [22] }\end{array}$ & $\begin{array}{l}\text { Mathematical multi-objective optimization model to } \\
\text { identify optimal product recovery solution }\end{array}$ \\
\hline Stochastic dynamic programming model [26] & $\begin{array}{l}\text { Mathematical optimization approach that sets } \\
\text { conditional EoL option for a sub-assembly based } \\
\text { on technical, legal and economic aspects }\end{array}$ \\
\hline Multi criteria matrix using AHP [19] & $\begin{array}{l}\text { MCDM approach: each component is assigned } \\
\text { ranking of EoL option }\end{array}$ \\
\hline Multi criteria for product EoL selection [5] & $\begin{array}{l}\text { MCDM: ranking of EoL option is implemented for } \\
\text { each component in a product }\end{array}$ \\
\hline $\begin{array}{l}\text { Remanufacturing product profile design tool } \\
\text { (REPRO2) [44] }\end{array}$ & $\begin{array}{l}\text { Empirical approach of eleven product profiles to to } \\
\text { design product accordingly }\end{array}$ \\
\hline Case based reasoning (CBR) [39] & $\begin{array}{l}\text { Empirical approach for suggesting EoL option for a } \\
\text { product as a whole }\end{array}$ \\
\hline
\end{tabular}

have focused on evaluating product recovery alternatives at strategic level. Table 2 presents EoL evaluation tools for a product at strategic level.

The literature survey shows that there is lack of a holistic approach that uses an inclusive methodology to assess and evaluate recovery strategies from an integrated point of view i.e. by taking into account technical, economic, environmental, business and societal aspects simultaneously. The research objective of this paper is therefore to answer the following questions: -

- Which key factors should be considered in the evaluation of product recovery strategies with respect to the relevant technical, economic, environmental, business and social criteria?

- How to assess product circularity strategies holistically by analysing the different types of factors?

\section{Research methodology}

The development process of product recovery multi-criteria decision tool (PR-MCDT) consists of three main phases; initial tool development based on literature, confrontation of the

Table 2 EoL decision tools for strategic evaluation of products [16]

\begin{tabular}{llll}
\hline Decision tool & Economic & Environmental & Social \\
\hline $\begin{array}{l}\text { Product EoL decision making methodology [33] } \\
\begin{array}{l}\text { Product EoL strategy selection algorithm Using } \\
\text { case base reasoning [15] }\end{array}\end{array}$ & $\mathrm{x}$ & $\mathrm{xx}$ & 0 \\
$\begin{array}{l}\text { Deployment model for part reuse in customised } \\
\quad \text { design of remanufactured products [7] }\end{array}$ & $\mathrm{xx}$ & $\mathrm{x}$ & 0 \\
$\begin{array}{l}\text { A custom-built decision tool called Repro2 to } \\
\text { product suitability based on product profiles [14] }\end{array}$ & $\mathrm{xx}$ & $\mathrm{x}$ & 0 \\
$\begin{array}{l}\text { Product Life Cycle Extension Techniques Selection } \\
\quad \text { PLEATS) model [11] }\end{array}$ & $\mathrm{x}$ & $\mathrm{x}$ & $\mathrm{x}$ \\
$\begin{array}{l}\text { Product EoL Strategy Selection algorism using } \\
\quad \text { fuzzy Logic and Bayesian updating [34] }\end{array}$ & $\mathrm{xx}$ & $\mathrm{x}$ & \\
$\begin{array}{l}\text { Extension of the End of Life Design Advisor } \\
\quad \text { ELDA) Using a neutral networking model [8] }\end{array}$ & $\mathrm{xx}$ & 0 & 0 \\
\hline
\end{tabular}


proposed tool to academics and industry practitioners, and final tool development. The development process of the tool is presented in Fig. 1. Subsequently, an explanation of each tool development phases is presented.

\section{Initial tool development}

A literature review is made to evaluate and analyse the available literature in the research area of EoL decision-making methods. The databases of Google Scholar, Science Direct, university's library Uni-Search \& ISI web of Science is used to gather and access relevant articles. The terms "End-of-Life Decision-making", "Circular Economy", and "Product Recovery Management" are used as keywords. Further information concerning product end-oflife decision making is gathered from reviewing corporate documents, marketing and publicity documentation, organization documentation and others. There are some renowned works on the research area of Product Recovery Management (PRM). Reading articles primarily related to End-of-Life product recovery decision making approaches had a significant role in this research work. The emphasis was given to understand end-of-life decision making approaches at strategic level.

A comprehensive literature review was undertaken to identify key end of life decisionmaking factors that used to evaluate product recovery strategies. Firstly, an exhaustive list of factors was presented and then the decision-making factors were sorted into main categories by the authors. Afterwards, factors from each category were evaluated based on literature review and expertise from G-SCOP laboratory. Based on the analysis, key decision-making factors were identified in regard to technical, economic, business, environmental and societal aspects and the most important factors were incorporated into decision making criteria. Based on findings from literature and feedback from expertise, the most important factors pertinent to consider in the decision-making process were accentuated.

The multi-criteria decision-making approach has been chosen as methodology to evaluate EoL product recovery strategies at strategic level. An iterative and multi-level procedure is used for selecting an appropriate multi-criteria decision-making methodology. The decisionmaking approach considers business, technical, legislative, market, economic, environmental and societal factors which will be integrated into the evaluation process.

\section{Improvement of the initial tool}

The initial product recovery multi-criteria decision tool (PR-MCDT) was presented at the international conference on remanufacturing - ICoR-2017 [1]. The venue was chosen to allow many members of sustainability community, both from industry and academia, to reflect on the

Fig. 1 Graphical depiction of the research methodology

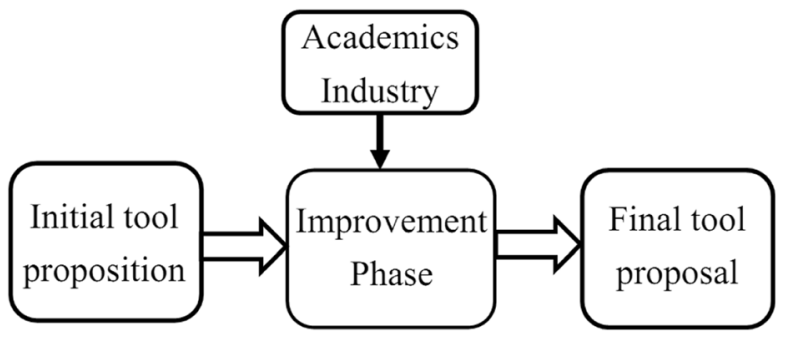


proposed tool. Verbal feedbacks were obtained and taken into consideration to improve the proposition. Table 3 presents a list of reviews along with their observations at ICoR 2017.

\section{Final tool development}

The proposed tool was revised and improved based on the suggestions from the ICoR2017 audience. Hence, the final version of the tool is presented as a contribution to the knowledge of this research. The following section presents the result and discusses the outcome of the research.

\section{The proposed methodology and tool}

\section{Multi-criteria decision tool}

A Product Recovery Multi-Criteria Decision Tool (PR-MCDT) is proposed for assessing product circularity strategies of a product at the end of its life. The six basic steps that grid the approach are as follows: (1) selection of potential end of life strategies, (2) scoping of end of life strategies, (3) selection of relevant indicators, (4) assessment of end of life strategies, (5) analysis and evaluation of end of life strategies, (6) refinement of strategies and final evaluation. Figure 2 and Figure 3 shows the mains steps and inputs of the multi-criteria decision tool respectively

MCDT is capable to consider product EoL selection holistically from an integrated point of view i.e. by simultaneously taking into account environmental, technical, economic, societal and business criteria. The main benefit of this methodology comprises, the decision maker has the opportunity to consider key decision factors such as legislation, new technologies and market demand in the end of life product recovery decision-making process. The decisionmaking approach also takes into account the preferences of the user in the evaluation process of end of life strategies. A brief description of each step of the tool is presented below.

\section{Selection of potential end of life strategies}

The definition of product recovery EoL strategies, constitutes the description of the product and associated potential EoL options. In this first step of MCDT approach, the decision-maker

Table 3 List of reviewer's positions along with their comments at ICoR 2017

\begin{tabular}{|c|c|c|}
\hline Reviewer & Position & Comments from reviewers \\
\hline A & $\begin{array}{l}\text { Director of The Centre for Sustainable Design \& } \\
\text { Academician at the University of the Creative } \\
\text { arts based in UK. }\end{array}$ & $\begin{array}{l}\text { The term end of life should be defined } \\
\text { well with reference to which type of } \\
\text { user (first user/last user) is considered } \\
\text { in the proposed tool. }\end{array}$ \\
\hline B & $\begin{array}{l}\text { Academics from Linköping University, Sweden } \\
\text { whose academic interest includes circular } \\
\text { economy, product recovery }\end{array}$ & $\begin{array}{l}\text { Quests how the tool is easily applied and } \\
\text { implemented in a recovery company }\end{array}$ \\
\hline $\mathrm{C}$ & $\begin{array}{l}\text { Representative from recovery company based in } \\
\text { Denmark and Belgium }\end{array}$ & $\begin{array}{l}\text { Highlights end of life decision factors } \\
\text { which are pertinent in which the } \\
\text { decision making process }\end{array}$ \\
\hline
\end{tabular}




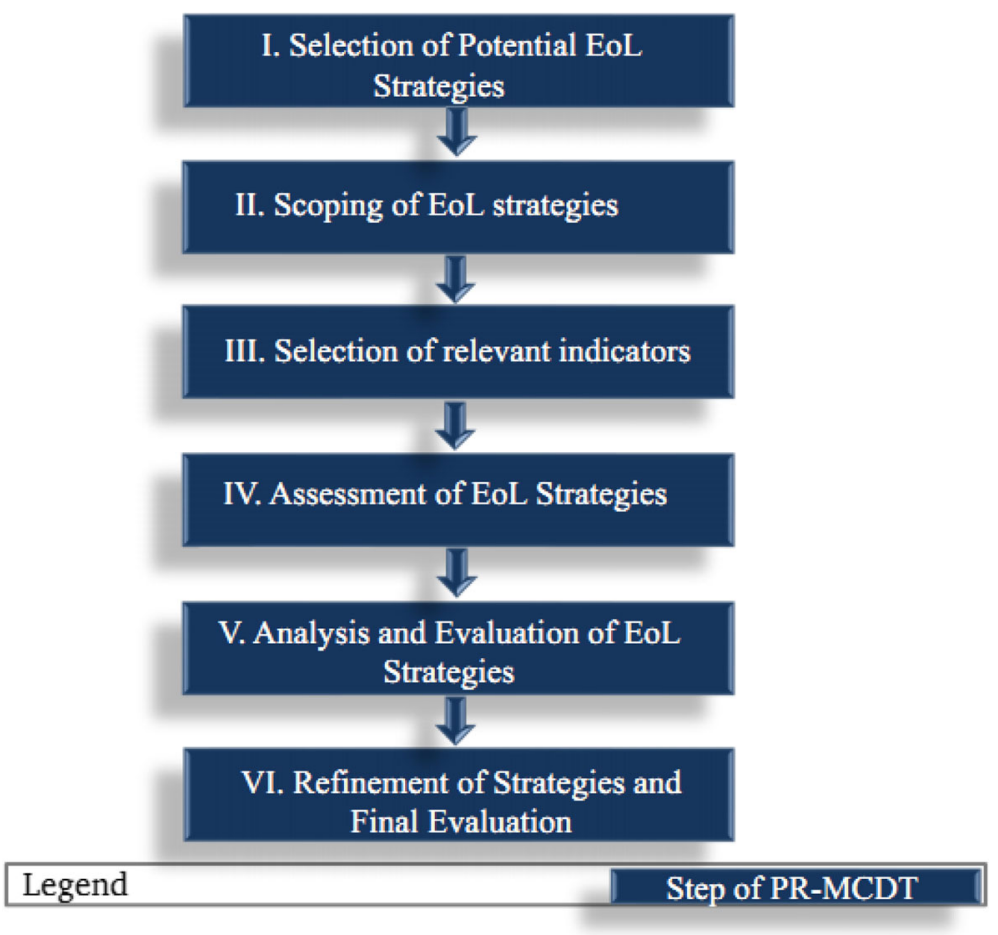

Fig. 2 Multicriteria decision tool (MCDT)

identifies potential EoL product recovery strategies and is unlimited by any constraints. The inputs to first step of MCDT are a list of product recovery strategies and the description of the product under study. The outcome of the stage of the process is a list of potential EoL strategies for a typical product.

Product recovery EoL options include Repair, Recondition, Remanufacture, Cannibalization, Refurbish and Recycle. Except recycle, they are strategies that re-create a product similar to the initial one in order to prolong its life. If it is not possible to re-create, the recycle strategy is defined to recover the material the components of the products are made of. The strategies that transform the product in a different product like upcycle, upgrade and repurpose are out of the scope of the study. Table 4 presents a summary of main product recovery strategies. An EoL option is considered as a product recovery strategy, if it fulfils three main criteria: collection of used products, reprocessing of a recovered product and redistribution of the processed product [6].

A potential product recovery EoL strategy is a possible candidate for evaluation and comparison during the decision-making process [38]. In multicriteria decision literatures, the list of potential candidate strategies are generally called alternatives or actions [28]. A functional description of the product is decisive for the recovery company to be able to achieve high level EoL treatment. The description of the product provides relevant information regarding the characteristics of the product as well as its functional use by the consumer [41].

Based on work in $[6,17,20-22,25,31,32,37]$, Table 4 outlines the following end-of-life product recovery options. 


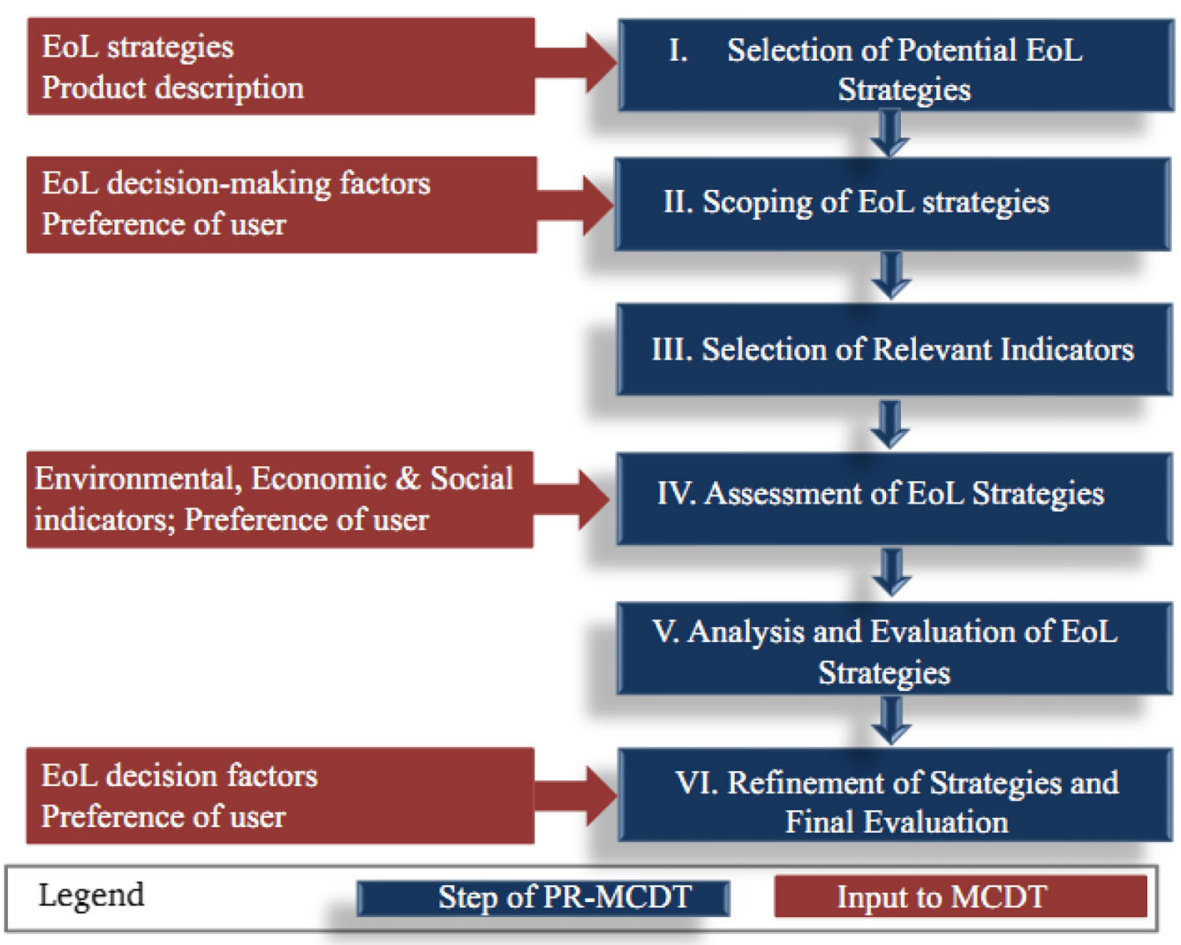

Fig. 3 MCDT input

\section{Scoping of end of life strategies}

After defining potential EoL strategies, this step gives the decision maker an opportunity to take a look of defined product recovery strategies against a set of feasibility criteria for the refinement of viable EoL recovery alternatives. The purpose of step 2 is to eliminate nonconforming scenarios during initial steps decision-making process based on various constraining influences such as technological, business, legislative and societal aspects that influence the feasibility of a particular EoL strategy.

Table 4 Product recovery strategy definitions

Remanufacture is an end of life product recovery strategy whereby used products are restored to the original equipment manufacturer (OEM) standard and receive a warranty at least equal to a newly manufactured product.

Recondition involves returning the quality of a product to a satisfactory state level (typically less than a virgin standard/new product) giving the resultant product a warranty less than of a newly manufactured equivalent.

Refurbishing involves returning products to a specific quality level, usually less than that of a new product. Reconditioned product has gone through extensive testing and repair than refurbished products.

Cannibalization is an activity of recovering parts from returned products. Recovered parts are used in repair, refurbishing, reconditioning and remanufacturing of other products.

Repair is an activity of returning a used product in to "working order" by fixing/replacing specified faults in a product using service parts.

Recycle is an activity where discarded materials are collected, processed and used in the production of new materials or products. 
The screening process of the EoL strategies is mainly qualitative. The selected EoL options from the screening process will be considered in the following steps of the decision-making process. The selection of a potential EoL product recovery option should be based on the information available related to the activity and experience of the decision-maker [24]. EoL decision-making factors and preference of the user are inputs for step 2 of the decision tool. A list of feasible strategies is the outcome at this stage of the decision-making process.

Table 5 shows a list of decision-making factors used in refinement of potential EoL strategies. Detailed explanation of how the list was created is presented in section "End of life decision making factors". Based on findings from literature and feedback from expertise from academia and industry practitioners, the most important decision factors (factors written in bold letters) pertinent to consider in the decision-making process were accentuated.

\section{Selection of relevant indicators}

The implementation of EoL strategy to recover a product at its end-of-life has environmental, economic and societal impacts. These impacts are measured by appropriate indicators to formulate a judgement on the selection of the best compromise for EoL strategies. The selection of relevant indicators may be accomplished from a predefined list where the decision-maker decides based on the EoL situation or develop his/her own individual indicators $[6,28]$. Table 6 shows a list of indicators. According to Bufardi et al. [5], the following criretias should be specified to decide EoL situation:-

Table 5 Categorization of EoL decision making factors

\begin{tabular}{|c|c|}
\hline Category & List of key factors \\
\hline Ecological (Environmental) & $\begin{array}{l}\text { *Human health }(\mathrm{HH}) \\
\text { *Ecosystem Quality (EQ) } \\
\text { *Resources (R) }\end{array}$ \\
\hline Legislation & $\begin{array}{l}\text { *Compliance with legislation/ EU legislation/WEEE } \\
\text { *Compliance with new legislation }\end{array}$ \\
\hline Market & $\begin{array}{l}\text { *Customer demand (Market demand) } \\
\text { *Competitive pressure }\end{array}$ \\
\hline Social & $\begin{array}{l}\text { *Additional job creation } \\
\text { *Level of customer satisfaction } \\
\text { *Consumer perception } \\
\text { *Safe working environment } \\
\text { *Customer relations }\end{array}$ \\
\hline Business & $\begin{array}{l}\text { *Return core volume } \\
* \text { Consumption model } \\
\text { *Degree of damage } \\
* \text { Return rate (Timing of product return) }\end{array}$ \\
\hline Economic & $\begin{array}{l}\text { *Financial cost of operating product recovery business } \\
\text { *Quality requirement of recovered product } \\
\text { *Resell price } \\
\text { *Possible obsolescence of an assembly }\end{array}$ \\
\hline Technical & $\begin{array}{l}\text { * Technical state (EoL condition of returned products) } \\
\text { *Advancement in technology } \\
\text { *Availability of recovery facilities } \\
\text { *Presence/Removability of Hazardous content } \\
\text { * Processibility } \\
\text { *Separability of materials }\end{array}$ \\
\hline
\end{tabular}


Table 6 List of indicators

\begin{tabular}{|c|c|c|c|}
\hline List of indicators (I) & Name & Unit & Goal \\
\hline \multirow[t]{4}{*}{ Environmental $\left(\mathrm{I}_{1}\right)$} & EoL impact indicator & Eco-indicator points $(\mathrm{Pt})$ & Minimizing \\
\hline & $\mathrm{CO}_{2}$ emissions & $\mathrm{Kg}$ & Minimizing \\
\hline & $\mathrm{SO}_{2}$ emissions & $\mathrm{Kg}$ & Minimizing \\
\hline & Energy consumption & KWh & Minimizing \\
\hline \multirow[t]{4}{*}{ Economic $\left(\mathrm{I}_{2}\right)$} & Net recoverable value & Euro & Maximizing \\
\hline & $\begin{array}{l}\text { Logistic cost (Collection } \\
\text { and transport cost) }\end{array}$ & Euro & Minimizing \\
\hline & Disassembly cost & Euro & Minimizing \\
\hline & $\begin{array}{l}\text { Product cost (What is paid for: } \\
\text { incineration, recycle, landfill, etc. }\end{array}$ & Euro & Minimizing \\
\hline \multirow[t]{2}{*}{ Societal $\left(\mathrm{I}_{3}\right)$} & $\begin{array}{l}\text { Number of employees to perform } \\
\text { the scenario }\end{array}$ & Integer number & Maximizing \\
\hline & $\begin{array}{l}\text { Exposure to hazardous materials } \\
\text { (Exposure of employees } \\
\text { to hazardous materials } \\
\text { in all operations) }\end{array}$ & $\begin{array}{l}\text { Qualitative Scale: 5-Very } \\
\text { important, 4-Important, } \\
\text { 3-medium, 2-low, } \\
\text { 1-very low }\end{array}$ & Minimizing \\
\hline
\end{tabular}

- Direction of preference: the direction of preference can be either maximization or minimization.

- Scale of measurement: the criteria can be measured on different scales depending on the availability of data and can be measured qualitatively or quantitatively.

- Unit of measurement: the criterion can be measured in different units depending on the nature of the data.

\section{Assessment of end of life strategies}

Once the end of life indicators and potential product recovery strategies are selected, the next step will be an evaluation of each EoL strategies with respect to the defined indicators. Potential EoL alternatives (Alt 1, Alt 2, Alt 3 ...Alt N) with respect to the evaluation indicators $\left(\mathrm{I}_{1}, \mathrm{I}_{2}, \mathrm{I}_{3} \ldots \mathrm{IN}\right)$ are presented in Table 7 [6]. After completing evaluation of strategies, strategies with a very bad (lowest) score is eliminated. End of life options which do not fail to have a worst value on any indicator are considered on the second evaluation [29].

Table 7 Table of evaluations

\begin{tabular}{|c|c|c|c|c|}
\hline & $\begin{array}{l}\text { Indicator } 1 \\
\mathrm{I}_{1}\end{array}$ & $\begin{array}{l}\text { Indicator } 2 \\
\mathrm{I}_{2}\end{array}$ & $\begin{array}{l}\text { Indicator } 3 \\
\mathrm{I}_{3}\end{array}$ & $\begin{array}{l}\text { Indicator } n \\
\text { In }\end{array}$ \\
\hline \multicolumn{5}{|c|}{ EoL alternative 1} \\
\hline Alt 1 & (Alt $1, I_{1}$ ) & (Alt $1, \mathrm{I}_{2}$ ) & (Alt $1, I_{3}$ ) & (Alt 1, In) \\
\hline \multicolumn{5}{|c|}{ EoL alternative 2} \\
\hline Alt 2 & (Alt 2, $\mathrm{I}_{1}$ ) & (Alt 2, $\mathrm{I}_{2}$ ) & $\left(\right.$ Alt $\left.2, I_{3}\right)$ & (Alt 2, In) \\
\hline \multicolumn{5}{|c|}{ EoL alternative 3} \\
\hline Alt 3 & (Alt 3, $\mathrm{I}_{1}$ ) & (Alt 3, I ${ }_{2}$ ) & $\left(\right.$ Alt $\left.3, I_{3}\right)$ & (Alt 3, In) \\
\hline \multicolumn{5}{|c|}{ EoL alternative 4} \\
\hline Alt 4 & (Alt 4, $\mathrm{I}_{1}$ ) & $\left(\right.$ Alt $\left.4, I_{2}\right)$ & (Alt 4, I I & (Alt 4, In) \\
\hline
\end{tabular}


The definition of some of the indicators for each dimension and how they are calculated is presented below.

- Economic indicator (I1):

\section{Net Recoverable Value (NRV)}

Repair value $=$ Value of component-Repair cost-Miscellaneous cost Recondition value $=$ Value of component-Recondition cost-Miscellaneous cost Remanufacture value $=$ Value of component - Remanufacture cost-Miscellaneous cost Miscellaneous cost $=$ Collection cost + Processing cost Economic value $=$ Value of component-Processing cost-Miscellaneous cost Net recoverable value $=$ EoL Economic Value-Disassembly cost Disassembly cost $=($ Labour to disassemble product $\times$ Labour rate $)+$ Tooling costs + Material costs + Overhead costs

\section{Disassembly cost}

Disassembly cost $=($ Labour to disassemble product $\times$ Labour rate $)+$ Tooling costs + Material costs + Overhead costs

\section{- Environmental indicator (I2):}

\section{End of Life impact on the Environment (EOLI)}

The end of life impact (EOLI) of a product can be computed during end of life retirement by eco-indicator [35]:

$$
\mathrm{EOLI}=\sum_{\mathrm{i}=1}^{\mathrm{N}_{\mathrm{T}}}\left(\mathrm{IE}_{\mathrm{i}} \mathrm{W}_{\mathrm{i}}\right)
$$

Where:

$\mathrm{N}_{\mathrm{T}}$ total number of materials in the product

$\mathrm{IE}_{\mathrm{i}}$ end of life impact of material $\mathrm{i}$

$\mathrm{W}_{\mathrm{i}} \quad$ weight of material i $(\mathrm{kg})$

$$
\sum_{i=1}^{N_{T}}\left(I_{i} W_{i}\right)=\text { end of life impact of component } i
$$

$\mathrm{n}$ number of materials in component $\mathrm{i}$

The eco-indicator values can be regarded as dimensionless figures. As a name eco-indicator is expressed in eco-indicator points (pt). In eco-indicator lists usually milli-indicator point $(\mathrm{mPt})$ is used which is one-thousandth of a Pt. The end of life impact of a material for a specific strategy can be refereed from eco-indicator table [29]. A positive point implies impact imposed on the environment while a negative impact infers impact which is avoided [28]. 


\section{- Social indicator (I3)}

Exposure to hazardous materials: - This indicator measures the exposure of employees to hazardous materials in all operations. It can be measured in a qualitative scale (5-very important; 4-important, 3-medium, 2-low, 1-very low). The goal is to minimize the exposure of employees to hazardous materials.

Number of employees: - It refers to the number of employees necessary to perform all operations associated with the scenario. It includes logistics, processing, disassembly etc. The goal is to maximize the number of employees for societal benefit.

\section{Analysis and evaluation of end of life strategies}

This step involves the ranking of EoL strategies based on the information retrieved from step 2 and the selected environmental, economic and social indicators in step 3. The information and data gathered from each step is critically evaluated to select the most appropriate EoL treatment strategy [6]. Due to the wide range of different multicriteria decision-making approaches, the choice of an appropriate method should be given great attention. It is critical for the decision maker to understand the problem, the feasible alternatives, conflicts between the criteria and level of uncertainty of the data before carrying out the choice to every multicriteria decision-making situation [6].

\section{Refinement of end of life strategies and final evaluation}

Once the analysis and ranking of potential EoL strategies is completed, further detail analysis should be applied by the decision maker to understand the consequences of selecting the best suitable strategy as a final solution. A critical evaluation of the potential best feasible product recovery strategy should be done against a set of criteria presented in Table 5. This step may result in acknowledgement of the candidate strategy as a final solution or may lead to a new iteration of the approach. In case, the user found the result to be unsatisfactory, then the next EoL option is considered and evaluated in the same way as the previous candidate. Alternatively, the procedure will be repeated by considering a new set of EoL strategies and/or a new family of indicators $[16,28]$.

\section{End of life decision making factors}

Findings from literature show that economic and environmental decision making factors are widely used to assess the viability of circularity strategies while neglecting other equally important factors such as legislation and societal factors [10, 30]. Social decision-making

Table 8 List of potential product recovery strategies

\begin{tabular}{ll}
\hline List of alternatives & Recovery strategy \\
\hline Alt 1 & $\begin{array}{l}\text { Reusing the product with minor service (Disassembly, } \\
\text { cleaning, polishing) } \\
\text { Remanufacturing } \\
\text { Alt } 2\end{array}$ \\
Alt 3 & Recycle \\
\hline
\end{tabular}


Table 9 List of selected indicators

\begin{tabular}{lllc}
\hline List of indicators & Name & Unit & Goal \\
\hline Environmental & Carbon footprint & Kg. CO2 & Minimize \\
Economic & Total revenue & Euro & Maximize \\
Societal & Exposure to hazardous materials & Quantitative scale 5. & Minimize \\
& & very important; 4-important, & \\
& & 3-medium, 2-low, 1-very low & \\
\hline
\end{tabular}

factors are most valuable to provide feasibility analysis of adopting a recovery strategy at strategic level. Furthermore, there is lack of a holistic approach for analysing and evaluating different types of factors simultaneously.

Based upon a comprehensive literature review and feedback from expertise in the subject domain, key end of life decision-making factors used to assess the feasibility of product recovery options were identified and presented (see Table 5). The decision-making factors are categorized into business, technical, economic, environmental, legal and societal aspects.

\section{Case study}

To exemplify the application of product recovery multi-criteria decision tool (PR-MCDT), an illustrative example of an automotive engine is carried out to show how the approach can be used. At the end of life, an engine can follow different routes that have its own consequences from economic, environmental, societal and business point of view. In this specific case, a light fiat engine, is considered with the evaluation of its main components (cylinder block, cylinder head, pistons, connecting rods, crankshaft, Flywheel, Camshaft \& Turbo) to simplify the complexity of the problem. The section is featured to follow the process defined in Fig. 2.

\section{Step I: Selection of potential end of life strategies}

The first step in this approach is to define the constitution of a set of potential EoL product recovery strategies. The selection of potential end-of-life strategies depends on the type of product and the associated product recovery option. In this specific case study, three potential end-of-life product recovery strategies are extracted from Tables 4. List of selected potential end-of-life strategies is presented in Table 8.

Table 10 Economic evaluation of EoL strategies

\begin{tabular}{|c|c|c|c|}
\hline Indicator 1 (Economic) & $\begin{array}{l}\text { EoL Alt. } 1 \\
\text { Reuse }\end{array}$ & $\begin{array}{l}\text { EoL Alt. } 2 \\
\text { Remanufacture }\end{array}$ & $\begin{array}{l}\text { EoL Alt. } 3 \\
\text { Recycle }\end{array}$ \\
\hline Revenue selling materials (£) & & & 108.46 \\
\hline Steel & & & 5.74 \\
\hline Cast iron & & & 34.85 \\
\hline Aluminium & & & 68.44 \\
\hline Revenue of selling engine $(£)$ & 162.00 & 2562.00 & \\
\hline Operating costs & 43.47 & 263.46 & 158.20 \\
\hline Energy consumption & 3.91 & 24.85 & 3.50 \\
\hline Workforce costs & 39.56 & 238.60 & 154.71 \\
\hline Total revenue $(£)$ & 568.53 & 2298.54 & -49.75 \\
\hline
\end{tabular}


Table 11 Environmental evaluation of EoL strategies

\begin{tabular}{llll}
\hline Indicator 2 (Environmental) & $\begin{array}{l}\text { EoL Alt. 1 } \\
\text { Reuse }\end{array}$ & $\begin{array}{l}\text { EoL Alt. 2 } \\
\text { Remanufacture }\end{array}$ & $\begin{array}{l}\text { EoL Alt. 3 } \\
\text { Recycle }\end{array}$ \\
\hline Kg CO2 eq. treatment process & 561 & 10,920 & 502 \\
Kg CO2 eq. recycling process & & 72,446 & 337,154 \\
Kg CO2 eq. avoided remanufacturing & 28,978 & 640,719 & 640,410 \\
Kg CO2 eq. avoided raw material extraction & 640,719 & $-702,245$ & $-302,754$ \\
Benefit & $-669,137$ & & \\
\hline
\end{tabular}

\section{Step II: Scoping of EoL strategies}

In this step, potential EoL strategies are evaluated against list of criteria categorized in to legislative, technical, business and societal aspects which is presented in Table 5. Nonconforming scenarios will be eliminated from the list while the remaining ones will be evaluated in the following steps. The selection of relevant EoL strategies depends on the preferences of the user (recovery company), the objective of the problem, experience of the user and constraints from social, market, legislation and technology. It is assumed that potential EoL alternatives of the automotive engine fairly satisfies those requirements. In general, few EoL strategies are interesting for the decision maker from a list of potential recovery options.

\section{Step III: Selection of relevant indicator}

Indicators from each dimension is selected to evaluate potential EoL alternatives. In this case study, societal indicator (exposure to hazardous materials), environmental (carbon footprint), and economic indicator (total revenue) is used (Table 9).

\section{Step IV: Assessment of end of life strategies}

The evaluation of EoL strategies with respect to economic and environmental indicator is presented in Table 10 and Table 11 respectively [30]. Also, evaluation of the societal indicator is shown in Table 12. The total revenue for realizing a recovery strategy is calculated by subtracting all costs incurred for implementing a recovery alternative from the revenue of selling the product/material. Based on the evaluation of the potential EoL strategies with the relevant indicators, the decision-maker can eliminate potential options which have very low result.

\section{Step V: Analysis and evaluation of end-of-life strategies}

In this case study, it appears that remanufacturing has better environmental and economic benefit over reuse and recycling strategies. In terms of societal benefit, reuse strategy

Table 12 Societal evaluation of EoL alternatives

\begin{tabular}{llll}
\hline Indicator 3 (Societal) & Reuse & Remanufacture & Recycle \\
\hline $\begin{array}{l}\text { Exposure to hazardous materials (Quantitative } \\
\quad \text { scale 5. very important; 4-important, } \\
\text { 3-medium, 2-low, 1-very low) }\end{array}$ & 2 & 3 & 4 \\
\hline
\end{tabular}


Table 13 Table of evaluation of EoL strategies

\begin{tabular}{|c|c|c|c|}
\hline Indicator & $\begin{array}{l}\text { EoL Alt. } 2 \\
\text { Remanufacture }\end{array}$ & $\begin{array}{l}\text { EoL Alt. } 1 \\
\text { Reuse }\end{array}$ & $\begin{array}{l}\text { EoL Alt. } 3 \\
\text { Recycle }\end{array}$ \\
\hline Economic total revenue $(\mathfrak{f})$ & 2298.54 & 568.53 & -49.75 \\
\hline Environmental benefit ( $\mathrm{Kg} \mathrm{CO} 2)$ & $-702,245$ & $-669,137$ & $-302,754$ \\
\hline $\begin{array}{l}\text { Societal - Exposure to hazardous materials } \\
\text { (Quantitative scale 5. very important; 4-important, } \\
\text { 3-medium, 2-low, 1-very low) }\end{array}$ & 3 & 2 & 4 \\
\hline
\end{tabular}

imposes less risk to the exposure of hazardous materials over remanufacturing and recycling strategies while remanufacturing imposes medium risk to exposer of hazardous material over employees. Even though, remanufacturing (EoL alternative 2) is the best compromise EoL strategy from an integrated point considering environmental, economic $\&$ societal indicators (Table 13).

\section{Step Vl: Refinement of strategies and final evaluation}

Before taking the final decision, EoL alternative 2 (Remanufacturing) should be examined in more detail following step II. Even if from a technical point of view, if remanufacturing of the automotive engine is possible, further investigation should be made to examine the selected strategy with list of pertinent decision-making factors like market demand and compliance with legislation. If it is realized that a the selected EoL option is unsatisfactory, another EoL option should be analysed again based on the ranking of the evaluation or the evaluation process is repeated with a consideration of alternative EoL strategies.

\section{Conclusion}

In this paper, we proposed a general product recovery multi-criteria decision tool (PR-MCDT) to evaluate product circularity strategies at strategic level. The decision-making tool uses a holistic approach, under several often-conflicting criteria, to assess the feasibility of recovery options with respect to relevant business, legal, environmental, social and economic factors and by taking in-to account the preferences of the decision maker.

Based on the analysis of literature and feedback form expertise, decision-making factors were also identified in regard to technical, economic, business, environmental and societal aspect. The paper also highlighted key decision-making criteria pertinent to consider in the decision-making process.

The paper dealt with important aspects related to the proposed approach such as definition of EoL strategies, selection of relevant indicators and exploitation of results. The proposed decision-making tool was also applied to an automotive engine case to illustrate the applicability of the approach. The results show that, remanufacturing is a feasible EoL option compared with repair and recycling strategies.

Acknowledgements We gratefully acknowledge the support of "Circ€uit"- Circular European Economy Innovative Training Network, the Marie Sklodowska-Curie Innovative Training Network, focusing on the circular economy as part of Horizon 2020 Programme of the European Commission. 
Open Access This article is distributed under the terms of the Creative Commons Attribution 4.0 International License (http://creativecommons.org/licenses/by/4.0/), which permits unrestricted use, distribution, and reproduction in any medium, provided you give appropriate credit to the original author(s) and the source, provide a link to the Creative Commons license, and indicate if changes were made.

Publisher's note Springer Nature remains neutral with regard to jurisdictional claims in published maps and institutional affiliations.

\section{References}

1. Alamerew YA, Brissaud D Evaluation of remanufacturing for product recovery : multi-criteria decision tool for end-of-life selection strategy. 3rd International Conference on Remanufacturing, Oct 2017, Linköping, Sweden. http://hal.univ-grenoble-alpes.fr/hal-01627790

2. Alamerew YA, Brissaud D (2018) Modelling and assessment of product recovery strategies through systems dynamics. Procedia CIRP 69:822-826

3. Asif FMA (2017) Circular manufacturing systems: a development framework with analysis methods and tools for implementation. $\mathrm{PhD}$ dissertation

4. Bocken NMP, Olivetti EA, Cullen JM, Potting J, Lifset R (2017) Taking the circularity to the next level: a special issue on the circular economy. J Ind Ecol 21:476-482

5. Bufardi A, Sakara D, Gheorghe R, Kiritsis D, Xirouchakis P (2003) Multiple criteria decision aid for selecting the best product end of life scenario. Int J Comput Integr Manuf 16:526-534

6. Bufardi A, Gheorghe R, Kiritsis D, Xirouchakis P (2004) Multicriteria decision-aid approach for product end-of-life alternative selection. Int J Prod Res 42:3139-3157

7. Cao H, Zhang L, Liu F (2010) Deployment model for part reuse in customized design of remanufactured products. Responsive Manuf - Green Manuf (ICRM 2010), 5th Int Conf : 7-12

8. Chen JL, Wu J (2003) Neural network model for product end-of-life strategies. IEEE Int Symp Electron Environ 159-164

9. Diaz R, Marsillac E (2017) Evaluating strategic remanufacturing supply chain decisions, Int J Prod Res 55(9):2522-2539. https://doi.org/10.1080/00207543.2016.1239848

10. Doyle K, Ijomah WL, Antony J (2012) Identifying the end of life decision making factors. Des. Innov. Value Towar. a Sustain. Soc. https://doi.org/10.1007/978-94-007-3010-6_102

11. Dunmade I (2004) PLETS model: a sustainability concept based approach to product end-of-life management. https://doi.org/10.1117/12.569629

12. Ellen MacArthur Foundation (2012) Circular Economy [Online]. https://www.ellenmacarthurfoundation.org/

13. Fellner J, Lederer J, Scharff C, Laner D (2017) Present potentials and limitations of a circular economy with respect to primary raw material demand. J Ind Ecol 21:494-496

14. Gehin A, Zwolinski P, Brissaud D (2008) A tool to implement sustainable end-of-life strategies in the product development phase. J Clean Prod 16:566-576

15. Ghazalli Z, Murata A. Development of an AHP - CBR evaluation system for remanufacturing: end-of-life selection strategy. (2011). doi: https://doi.org/10.1080/19397038.2010.528848

16. Goodall P, Rosamond E, Harding J (2014) A review of the state of the art in tools and techniques used to evaluate remanufacturing feasibility. J Clean Prod 81:1-15

17. He W, Li G, Ma X, Wang H, Huang J, Xu M, Huang C (2006) WEEE recovery strategies and the WEEE treatment status in China. J Hazard Mater 136:502-512

18. Hosseinzadeh M, Roghanian E (2012) An optimization model for reverse logistics network under stochastic environment using genetic algorithm. Int J Bus Soc Sci 3

19. Iakovou E, Moussiopoulos N, Xanthopoulos A, Achillas C, Michailidis N, Chatzipanagioti M, Koroneos C, Bouzakis KD, Kikis V (2009) A methodological framework for end-of-life management of electronic products. Resour Conserv Recycl 53:329-339

20. Ijomah WL (2004) A model-based definition of the generic remanufacturing business process. $\mathrm{PhD}$ dissertion, Univ. Plymouth, UK

21. Jawahir IS, Bradley R (2016) Technological elements of circular economy and the principles of 6 R-based closed-loop material flow in sustainable manufacturing. Procedia CIRP 40:103-108

22. King AM, Burgess SC, Ijomah W, McMahon CA (2006) Reducing waste: repair, recondition, remanufacture or recycle? Sustain Dev 14:257-267. https://doi.org/10.1002/sd.271

23. Kirchherr J, Reike D, Hekkert M (2017) Conceptualizing the circular economy: an analysis of 114 definitions. Resour Conserv Recycl 127:221-232 
24. Kiritsis D, Bufardi A, Xirouchakis P. Multi-criteria decision aid for product end of life options selection. Proc. 2003 IEEE Int. Symp. Electron. Environ. Boston, MA.

25. Krikke HR (1998) Recovery strategies and reverse logistic network design. Institute of Business Engineering and Technology Application (BETA), Universiteit Twente, Enschede, The Netherlands. PhD thesis

26. Krikke HR, van Harten A, Schuur PC (1998) On a medium term product recovery and disposal strategy for durable assembly products. Int J Prod Res 36:111-139

27. Kumar V, Shirodkar PS, Camelio JA, Sutherland JW (2007) Value flow characterization during product lifecycle to assist in recovery decisions. Int J Prod Res 45(18-19):4555-4572

28. Lamvik T, Myklebust O, Miljeteig G (2002) The AEOLOS methodology. IEEE Int Symp Electron Environ. https://doi.org/10.1109/ISEE.2002.1003287

29. Lee SG, Lye SW, Khoo MK (2001) A multi-objective methodology for evaluating product end-of-life options and disassembly. Int J Adv Manuf Technol 18:148-156. https://doi.org/10.1007/s001700170086

30. Luglietti R, Taisch M, Magalini F, Cassina J, Mascolo JE (2014) Environmental and economic evaluation of end-of- life alternatives for automotive engine. In: 2014 International ICE Conference on Engineering, Technology and Innovation (ICE). IEEE pp. 1-9

31. Matsumoto M, Ijomah W (2013) Remanufacturing. In: Kauffman J, Lee K (eds) Handb. Sustain. Eng. https://doi.org/10.1007/978-1-4020-8939-8

32. Paterson DAP, Ijomah WL, Windmill JFC (2014) End-of-life decision tool with emphasis on remanufacturing. J Clean Prod. https://doi.org/10.1016/j.jclepro.2017.02.011

33. Pochampally KK, Gupta SM (2012) Use of linear physical programming and Bayesian updating for design issues in reverse logistics. Int J Prod Res 50:1349-1359

34. Pochampally KK, Vadde S, Kamarthi VS, Gupta SM (2004) Beyond sensor-assisted diagnosis of used products. Proc. SPIE 5583, Environmentally Conscious Manufacturing IV. https://doi.org/10.1117/12.571543

35. Pré Consultants (2000) Eco-indicator 99 Manual for Designers [Online]. Minist Housing, Spat Plan Environ. http://www.pre-sustainability.com/download/manuals/EI99_Manual.pdf

36. Ravi V, Shankar R, Tiwari MK (2005) Analyzing alternatives in reverse logistics for end-of-life computers: ANP and balanced scorecard approach. Comput Ind Eng 48:327-356

37. Rose M (2000) Design for environment: a method for formulating end-of-life strategies. PhD Thesis, Department of Mechanical Engineering, Stanford University, pp. 19-144

38. Roy B (1996) Multicriteria methodology for decision aiding, volume Nonconvex Optimization and Its Applications. Kluwer Academic Publishers, Dordrecht

39. Shih LH, Chang YS, Lin YT (2006) Intelligent evaluation approach for electronic product recycling via case-based reasoning. Adv Eng Inform 20:137-145

40. Stewart D, Ijomah W (2011) Moving forward in reverse: a review into strategic decision making in reverse logistics. In: International Conference on Remanufacturing - ICoR, 2011-07-27 - 2011-07-29, University of Strathclyde

41. Sundin E (2004) Product and process design for successful remanufacturing

42. Thierry M, Salomon M, Vannunen J, Vanwassenhove L (1995) Strategic issues in product recovery management. Calif Manag Rev 37:114-135

43. Ziout A, Azab A, Atwan M (2014) A holistic approach for decision on selection of end-of-life products recovery options. J Clean Prod 65:497-516

44. Zwolinski P, Lopez-Ontiveros MA, Brissaud D (2006) Integrated design of remanufacturable products based on product profiles. J Clean Prod 14:1333-1345. https://doi.org/10.1016/j.jclepro.2005.11.028 